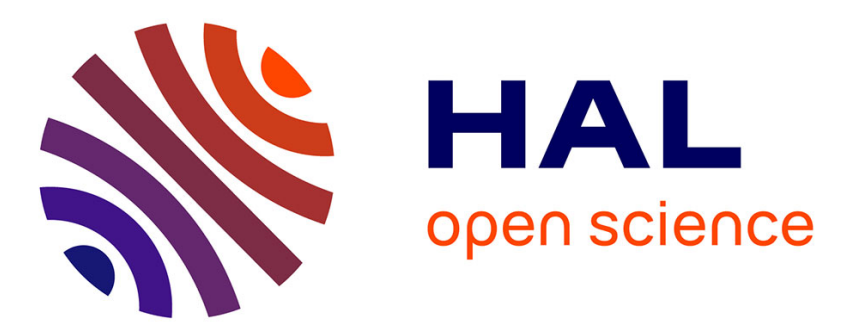

\title{
Poly(ethylene glycol) as reaction medium for mild Mizoroki-Heck reaction in a ball-mill
}

Valérie Declerck, Evelina Colacino, Xavier Bantreil, Jean Martinez, Frédéric Lamaty

\section{- To cite this version:}

Valérie Declerck, Evelina Colacino, Xavier Bantreil, Jean Martinez, Frédéric Lamaty. Poly(ethylene glycol) as reaction medium for mild Mizoroki-Heck reaction in a ball-mill. Chemical Communications, 2012, 48 (96), pp.11778-11780. 10.1039/c2cc36286d . hal-00784597

\section{HAL Id: hal-00784597 \\ https://hal.science/hal-00784597}

Submitted on 12 Feb 2021

HAL is a multi-disciplinary open access archive for the deposit and dissemination of scientific research documents, whether they are published or not. The documents may come from teaching and research institutions in France or abroad, or from public or private research centers.
L'archive ouverte pluridisciplinaire HAL, est destinée au dépôt et à la diffusion de documents scientifiques de niveau recherche, publiés ou non, émanant des établissements d'enseignement et de recherche français ou étrangers, des laboratoires publics ou privés. 


\title{
Poly(ethylene glycol) as reaction medium for mild Mizoroki-Heck reaction in a ball-mill $\dagger$
}

\author{
Valérie Declerck, $\ddagger$ Evelina Colacino, Xavier Bantreil, Jean Martinez and Frédéric Lamaty*
}

\begin{abstract}
Phosphine-free palladium-catalyzed Mizoroki-Heck reaction was performed using ball-milling in polyethylene glycol under mild conditions. Good to excellent yields of coupling products were obtained. This activation technique also allowed the concomitant formation of round shaped Pd-PEG nanoparticles that were characterized by TEM analysis.
\end{abstract}

Grinding, dry mixing or ball-milling have proved their efficiency as unconventional techniques in the field of organic chemistry in solid state. ${ }^{1}$ These techniques have been applied to a large number of organic transformations, but with limited use in the case of $\mathrm{C}-\mathrm{C}$ bond formation, to aldol and Knoevenagel condensations, Michael additions, Baylis-Hillman and Wittig reactions, and asymmetric alkylation of Schiff bases. ${ }^{2}$ Transition metal-catalyzed coupling reactions, especially with palladium, are very efficient and well developed $\mathrm{C}-\mathrm{C}$ bond formation reactions. ${ }^{3}$ Such reactions performed in a ball-mill have been limited to a small number of examples of transformations, mainly the Suzuki-Miyaura ${ }^{4}$ and Mizoroki-Heck ${ }^{5}$ cross couplings.

In the last few years we have developed a metal-based catalytic system using solid PEGs [poly(ethylene glycols)] as solvent and stabilizing/precipitating agents to separate the organic product from the metallic catalytic system. ${ }^{6}$ We questioned whether the use of solid PEG would be adapted to the development of a useful catalytic system to perform Pd-catalyzed reactions in a ball-mill.

As a model reaction, the Mizoroki-Heck arylation ${ }^{7}$ of tertbutyl acrylate to produce cinnamate was chosen. A mixture of $\mathrm{PhI}$, tert-butyl acrylate, $\mathrm{PEG}, \mathrm{Pd}(\mathrm{OAc})_{2}$ and an inorganic base was reacted in a high energy stainless steel vibratory ball mill for $1 \mathrm{~h}$ at $30 \mathrm{~Hz}$ together with additives in some cases. Under traditional heating and microwave irradiation, $\mathrm{PEG}$ has already been shown to reduce $\mathrm{Pd}(\mathrm{OAc})_{2}$ to $\mathrm{Pd}(0) .{ }^{6 d, 8}$ However, under ball-milling conditions, it was found necessary to add

Institut des Biomolécules Max Mousseron (IBMM),

CNRS-Universités Montpellier 1 et 2, Place Eugène Bataillon, 34095 Montpellier Cedex 5, France.

E-mail: frederic.lamaty@univ-montp2.fr; Fax: +33(0)467144866

$\ddagger$ Present address: Laboratoire de Synthèse Organique et Méthodologie, ICMMO (UMR 8182-CNRS), Université Paris-Sud 11, 15 rue Georges Clemenceau, 91405 Orsay cedex, France. sodium formate as a reducing agent for the activation of $\mathrm{Pd}(\mathrm{OAc})_{2}(67 \%$ yield $)$. This was the best from a practical point of view, as sodium formate is easy to handle, as well as from the results obtained with reducing agents such as $\mathrm{H}_{2}(28 \%)$ or $\mathrm{NaBH}_{4}(59 \%)$. At the end of the reaction, the mixture was dissolved in a small amount of $\mathrm{CH}_{2} \mathrm{Cl}_{2}$ and precipitated in ether, filtered, evaporated and analyzed by ${ }^{1} \mathrm{H}$ NMR using $\mathrm{CH}_{2} \mathrm{Br}_{2}$ as an internal standard. Integration of the signal corresponding to the $\mathrm{H}$ of the ester group of tertbutylcinnamate measured against the unique signal of the standard $\left(\mathrm{CH}_{2} \mathrm{Br}_{2}\right)$ provided the yield of the product. Results are presented in Table 1.

It was shown previously that a solid additive like sodium chloride could be valuable for the Mizoroki-Heck arylation reaction. ${ }^{5}$ In our study, when PEG-3400-OH was used, adding $\mathrm{NaCl}$ was found to be detrimental to the reaction and barely any conversion was observed whilst $67 \%$ yield was obtained in the absence of $\mathrm{NaCl}$ (entries 1-2). Attempt to change the inorganic base by switching from $\mathrm{K}_{2} \mathrm{CO}_{3}$ to $\mathrm{Na}_{2} \mathrm{CO}_{3}$ (entry 3) resulted in a lower conversion most probably because the $\mathrm{PEG}-\mathrm{K}^{+}$interaction is stronger than the corresponding PEG- $-\mathrm{Na}^{+}$thus enhancing the base activity. When triethylamine

Table 1 Optimization of ball-milling Mizoroki-Heck reaction ${ }^{a}$

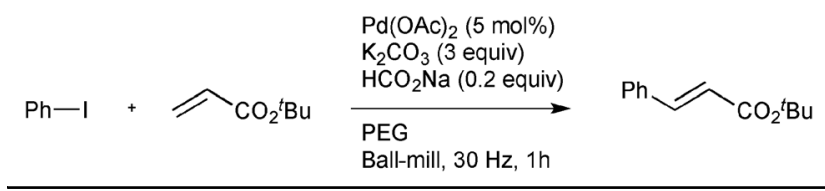

\begin{tabular}{llllc}
\hline Entry & PEG & Acrylate (equiv.) & Additive & Yield $^{b}(\%)$ \\
\hline 1 & PEG-3400-OH & 1.2 & $\mathrm{NaCl}$ & 0.4 \\
2 & PEG-3400-OH & 1.2 & - & 67 \\
$3^{c}$ & PEG-3400-OH & 1.2 & - & 2 \\
4 & PEG-2000-OH & 1.2 & - & 88 \\
$5^{d}$ & PEG-2000-OH & 1.2 & - & 0 \\
6 & PEG-2000-OH & 5 & - & 100 \\
7 & MeO-PEG-2000-OMe & 5 & - & 46 \\
8 & MeO-PEG-2000-OH & 5 & - & 27 \\
9 & PEG-1100-OH & 5 & - & 0 \\
10 & - & 1.2 &
\end{tabular}

${ }^{a}$ Reaction conditions: phenyl iodide $(0.1 \mathrm{mmol})$, tert-butyl acrylate, $\mathrm{Pd}(\mathrm{OAc})_{2}(5 \mathrm{~mol} \%), \mathrm{HCO}_{2} \mathrm{Na}$ (0.2 equiv.), $\mathrm{K}_{2} \mathrm{CO}_{3}$ (3 equiv.), $\mathrm{PEG}$ (110 mg). ${ }^{b}$ Yields were determined by ${ }^{1} \mathrm{H}$ NMR using $\mathrm{CH}_{2} \mathrm{Br}_{2}$ as an internal standard. ${ }^{c} \mathrm{Na}_{2} \mathrm{CO}_{3}$ was used instead of $\mathrm{K}_{2} \mathrm{CO}_{3} .{ }^{d} 1 \mathrm{~mol} \%$ $\mathrm{Pd}(\mathrm{OAc})_{2}$. 
was used, substrates also remained unchanged. We realized that during the course of the reaction, it appeared that PEG melted due to the slight heating of the ball-mill. ${ }^{9}$ As the viscosity of the PEG used might have an influence on the reaction, we turned our attention to shorter polymers having a lower melting point. As a result, the yield increased by $20 \%$ by using PEG-2000-OH (entry 4 ). While reducing catalyst loading to $1 \mathrm{~mol} \%$ resulted in no conversion (entry 5), increasing the quantity of acrylate from 1.2 to 5 equivalents resulted in total conversion (entry 6). The exact excess amount of acrylate needed for completion of the reaction was not studied in detail. Several PEGs were then tested under these conditions. The use of mono- and di-methylated PEG-2000 was detrimental as the yields dropped down (entries 7 and 8). Finally, shorter PEG-1100-OH gave a $74 \%$ yield (entry 9). It is worth noting that due to the stabilizing effect of oxygen atoms in PEG, no phosphine ligand was necessary for the catalysis. In the absence of PEG, no reaction occurred (entry 10). In addition, Mizoroki-Heck coupling generally requires elevated temperatures, unfriendly solvent and an inert atmosphere. In our study, the use of PEG in a vibratory ball-mill allowed the reaction to proceed in air under mild conditions.

The scope of the reaction was first explored by varying the olefin part. Unfortunately, the reaction was efficient only with tert-butyl acrylate. Either no reaction was observed or a very poor yield was obtained with acrylonitrile $(0 \%)$, acrylamide $(0 \%)$, methyl methacrylate $(5 \%)$ or styrene $(13 \%)$. The aromatic partner was then evaluated (Table 2). Different substituents could be used on the aryl moiety. ${ }^{10}$ Electron-donating as well as withdrawing groups were well tolerated in the para position as $p$-MeO, $p$-CN, $p$ - $\mathrm{Br}$ gave satisfactory yields (entries 2-4) and $p$-CHO was converted quantitatively (entry 5). Surprisingly, $p-\mathrm{NO}_{2}$ substitution resulted in poor yield (entry 6). This is may be due to a physico-chemical characteristic of the starting 4-iodo nitrobenzene rather than

Table 2 Exemplification of the ball-milling Mizoroki-Heck reaction ${ }^{a}$

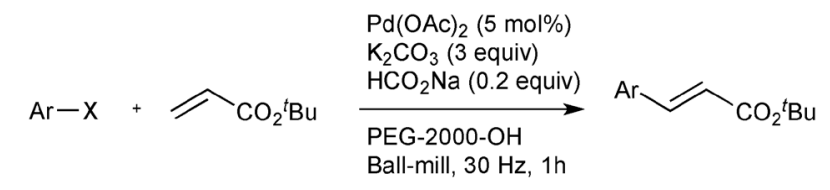

\begin{tabular}{lllc}
\hline Entry & ArX & Additive & Yield $^{b}(\%)$ \\
\hline 1 & $\mathrm{PhI}$ & - & 100 \\
2 & $4-\mathrm{MeO}-\mathrm{C}_{6} \mathrm{H}_{4}-\mathrm{I}$ & - & 73 \\
3 & $4-\mathrm{NC}-\mathrm{C}_{6} \mathrm{H}_{4}-\mathrm{I}$ & - & 62 \\
4 & $4-\mathrm{Br}-\mathrm{C}_{6} \mathrm{H}_{4}-\mathrm{I}$ & - & 68 \\
5 & $4-\mathrm{OHC}-\mathrm{C}_{6} \mathrm{H}_{4}-\mathrm{I}$ & - & 100 \\
6 & $4-\mathrm{O}_{2} \mathrm{~N}-\mathrm{C}_{6} \mathrm{H}_{4}-\mathrm{I}$ & - & 35 \\
7 & $3-\mathrm{F}-\mathrm{C}_{6} \mathrm{H}_{4}-\mathrm{I}$ & - & 100 \\
8 & $2-\mathrm{Me}-\mathrm{C}_{6} \mathrm{H}_{4}-\mathrm{I}$ & - & 29 \\
9 & $\mathrm{PhBr}$ & - & 0 \\
10 & $\mathrm{PhBr}$ & NaI & 0 \\
11 & $\mathrm{PhCl}$ & - & 0 \\
12 & $\mathrm{PhCl}$ & NaI & 0
\end{tabular}

${ }^{a}$ Reaction conditions: phenyl iodide $(0.1 \mathrm{mmol})$, tert-butyl acrylate ( $0.5 \mathrm{~mol}), \mathrm{Pd}(\mathrm{OAc})_{2}(5 \mathrm{~mol} \%), \mathrm{HCO}_{2} \mathrm{Na}\left(0.2\right.$ equiv), $\mathrm{K}_{2} \mathrm{CO}_{3}$ (3 equiv.), PEG-2000-OH $(110 \mathrm{mg}) .{ }^{b}$ Yields were determined by ${ }^{1} \mathrm{H}$ NMR using $\mathrm{CH}_{2} \mathrm{Br}_{2}$ as an internal standard. an electronic effect of the substituent. A fluorine atom in the meta position allowed quantitative conversion (entry 7). However, having a methyl group in the ortho position reduced the yield to $29 \%$ (entry 8 ). Finally, the influence of the halide leaving group (I vs. $\mathrm{Br}, \mathrm{Cl}$ ) was explored. Only the iodine atom was reactive enough to provide the expected product, even when sodium iodide was added to the reaction mixture (entries 9-12).

It has already been demonstrated that palladium salts in the presence of polyethylene glycol are transformed into nanoparticles by classical activation. Because the order of the reduction potentials of the polyol and noble metals is not favorable at $\mathrm{rt}$, this method requires high temperatures to reduce the noble metals. ${ }^{11}$ This was confirmed by our previous work, using convection ${ }^{6 g}$ or microwave heating. ${ }^{6 d}$ Furthermore, when a long chain PEG (PEG-2000-OH or PEG-4000-OH) in the presence of $\mathrm{Pd}(\mathrm{OAc})_{2}$ but no substrate was stirred at a temperature of $80-120{ }^{\circ} \mathrm{C}$, nanoparticles of $5 \mathrm{~nm}$ were observed. ${ }^{8}$ When using PEG-400-OH, phenanthroline as a reducing agent was necessary to observe the formation of 2-6 $\mathrm{nm}$ particles. ${ }^{12}$ However, under vibrating ball-milling conditions, since the reaction temperature was mild, ${ }^{9}$ an external reducing agent such as sodium formate was required for activation of $\mathrm{Pd}(\mathrm{OAc})_{2}$.

According to these results, we questioned whether formation of nanoparticles would also occur in the ball mill during the course of the reaction, knowing that physical and chemical properties would depend on the size and shape of the particles. Transition Electron Microscopy (TEM) analysis of the precipitates obtained after reactions reported in Table 1 with various PEGs was performed (Fig. 1, left column). In order to compare, experiments were run under the same reaction conditions but in the absence of phenyl iodide and tert-butyl acrylate (Fig. 1, right column). In all cases, light yellow $\mathrm{Pd}(\mathrm{OAc})_{2}$ was transformed into a deep brown solid, indicating the formation of $\mathrm{Pd} / \mathrm{PEG}$ nanoparticles. TEM analysis confirmed this experimental assumption (Fig. 1). To our knowledge, this represents the first example of generation of Pd-polymer nanoparticles using a ball-mill. ${ }^{13}$ In the absence of substrates, the reaction led to significant particle aggregation, regardless of the PEG used. When substrates were present, the aggregation was less important and nice round-shaped nanoparticles could be obtained. The size of nanoparticles is directly connected to the size of the polymer. Indeed, the average size of the nanoparticles observed was 6-8 nm, 8-11 nm and 7-13 nm with PEG-1100-OH, PEG2000-OH and PEG-3400-OH, respectively (Fig. 1a, c and e). In addition, with PEG-3400-OH, particles were found to be slightly more elliptical than with other polymers. Surprisingly, when PEG-2000-OH was mono- or di-methylated, the particle size changed to $7-13 \mathrm{~nm}$ and $5-7 \mathrm{~nm}$, respectively (Fig. $1 \mathrm{~g}$ and i).

Formation of palladium nanoparticles in PEG after a Mizoroki-Heck reaction activated by microwave irradiation and TEM analysis has already been reported. In PEG$400-\mathrm{OH}$, which is a liquid polymer, particles of 5-8 $\mathrm{nm}$ were obtained. ${ }^{14}$ In PEG-3400-OH, following benzazepine synthesis, TEM analysis of the catalytic system revealed aggregated particles of 5-7 nm. ${ }^{6 d}$ The particle aspect was quite different from those shown in Fig. 1 (left column). Thus, the activation 

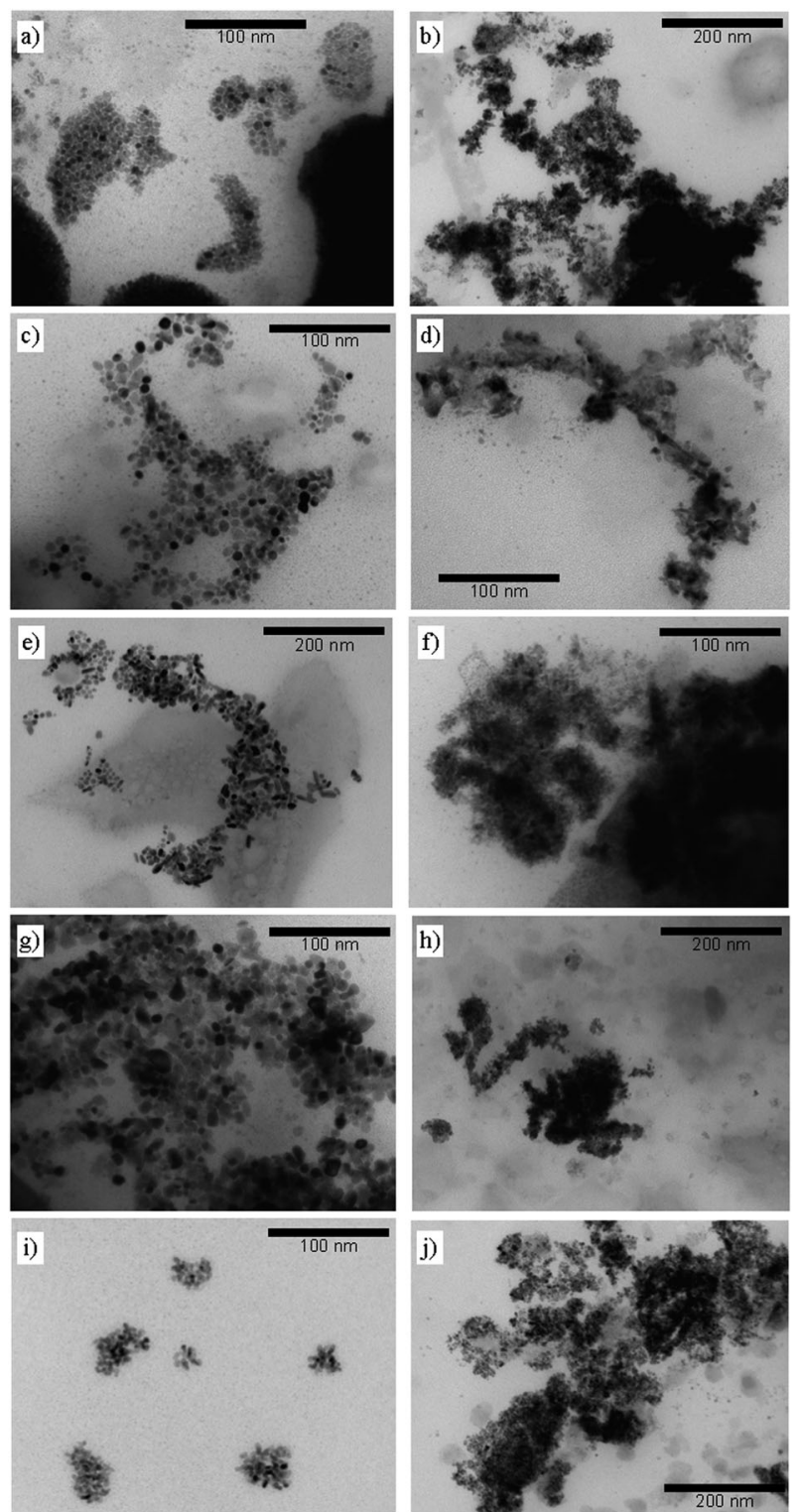

Fig. 1 TEM images of PEG-Pd nanoparticles obtained after MizorokiHeck reaction (left column) and without substrates (right column) in different PEGs: (a, b) PEG-1100-OH; (c, d) PEG-2000-OH; (e, f) PEG-3400-OH; (g, h) MeO-PEG-2000-OH; (i, j) MeO-PEG2000-OMe.

method seems to have a strong influence on the size and aggregation state of the nanoparticles.

We reported herein a solvent-free/phosphine-free palladiumcatalyzed Mizoroki-Heck procedure in a ball mill. Under mild conditions, quantitative yields were obtained using the appropriate polymer PEG-2000-OH, with a correct tolerance toward functional groups on the aryl moiety. Nanoparticles formed during these reactions were characterized by TEM and were found to be size-dependent on the PEG used. In addition, activation using ball-milling yielded nanoparticles different from those obtained previously using convection or microwave heating.
We are grateful to the "Service Commun de Microscopie Electronique et Analytique" of the University Montpellier 2 for TEM analysis and fruitful discussions.

\section{Notes and references}

1 K. Tanaka and F. Toda, Chem. Rev., 2000, 100, 1025-1074.

2 (a) S. L. James, C. J. Adams, C. Bolm, D. Braga, P. Collier, T. Friscic, F. Grepioni, K. D. M. Harris, G. Hyett, W. Jones, A. Krebs, J. Mack, L. Maini, A. G. Orpen, I. P. Parkin, W. C. Shearouse, J. W. Steed and D. C. Waddell, Chem. Soc. Rev., 2012, 41, 413-447; (b) R. B. N. Baig and R. S. Varma, Chem. Soc. Rev., 2012, 41, 1559-1584; (c) P. Nun, V. Pérez, M. Calmès, J. Martinez and F. Lamaty, Chem.-Eur. J., 2012, 18, 3773-3779; (d) B. Rodríguez, A. Bruckmann, T. Rantanen and C. Bolm, Adv. Synth. Catal., 2007, 349, 2213-2233; (e) F. Alonso, I. P. Beletskaya and M. Yus, Tetrahedron, 2005, 61, 11771-11835.

3 (a) S. Bräse and A. De Meijere, in Handbook of Organopalladium Chemistry for Organic Synthesis, John Wiley \& Sons, Inc., 2002, vol. 1, pp. 1223-1254; (b) M. Larhed and A. Hallberg, in Handbook of Organopalladium Chemistry for Organic Synthesis, John Wiley \& Sons, Inc., 2002, vol. 1, pp. 1133-1178.

4 (a) F. Schneider, A. Stolle, B. Ondruschka and H. Hopf, Org. Process Res. Dev., 2008, 13, 44-48; (b) J.-H. Li, C.-L. Deng and Y.-X. Xie, Synth. Commun., 2007, 37, 2433-2448; (c) S. F. k. Nielsen, D. Peters and O. Axelsson, Synth. Commun., 2000, 30, 3501-3509; (d) L. M. Klingensmith and N. E. Leadbeater, Tetrahedron Lett., 2003, 44, 765-768.

5 (a) E. Tullberg, F. Schacher, D. Peters and T. r. Frejd, Synthesis, 2006, 1183-1189; (b) E. Tullberg, D. Peters and T. r. Frejd, J. Organomet. Chem., 2004, 689, 3778-3781.

6 (a) E. Colacino, J. Martinez, F. Lamaty, L. S. Patrikeeva, L. L. Khemchyan, V. P. Ananikov and I. P. Beletskaya, Coord Chem. Rev., 2012, DOI: 10.1016/j.ccr.2012.05.027; (b) X. Bantreil, M. Sidi-Ykhlef, L. Aringhieri, E. Colacino, J. Martinez and F. Lamaty, J. Catal., 2012, 294, 113-118; (c) E. Colacino, L. Villebrun, J. Martinez and F. Lamaty, Tetrahedron, 2010, 66, 3730-3735; (d) V. Declerck, P. Ribiere, Y. Nedellec, H. Allouchi, J. Martinez and F. Lamaty, Eur. J. Org. Chem., 2007, 201-208; (e) E. Colacino, L. Daich, J. Martinez and F. Lamaty, Synlett, 2007, 1279-1283; (f) V. Declerck, J. Martinez and F. Lamaty, Synlett, 2006, 3029-3032; ( $g$ ) P. Ribiere, V. Declerck, Y. Nedellec, N. Yadav-Bhatnagar, J. Martinez and F. Lamaty, Tetrahedron, 2006, 62, 10456-10466.

7 I. P. Beletskaya and A. V. Cheprakov, Chem. Rev., 2000, 100, 3009-3066.

8 C. Luo, Y. Zhang and Y. Wang, J. Mol. Catal. A: Chem., 2005, 229, 7-12.

9 E. Colacino, P. Nun, F. M. Colacino, J. Martinez and F. Lamaty, Tetrahedron, 2008, 64, 5569-5576.

10 Typical procedure for the ball-mill Mizoroki-Heck reaction: in a $10 \mathrm{~mL}$ stainless steel ball-mill reactor were added $\mathrm{Pd}(\mathrm{OAc})_{2}$ (1.1 mg, $0.005 \mathrm{mmol}$ ), $\mathrm{K}_{2} \mathrm{CO}_{3}$ (41.4 mg, $\left.0.3 \mathrm{mmol}\right), \mathrm{HCO}_{2} \mathrm{Na}$ (1.4 mg, $0.02 \mathrm{mmol})$ and PEG-2000-OH (110 mg). Phenyl iodide $(11.2 \mu \mathrm{L}, 0.1 \mathrm{mmol})$, tert-butyl acrylate $(73.2 \mu \mathrm{L}, 0.5 \mathrm{mmol})$ and two stainless steel balls with a $7 \mathrm{~mm}$ diameter were then added. The mixture was then subjected to high speed vibration milling for $1 \mathrm{~h}$ at $30 \mathrm{~Hz}$ on a Retsch MM200. A minimum of $\mathrm{CH}_{2} \mathrm{Cl}_{2}$ was then added and the mixture was precipitated in $\mathrm{Et}_{2} \mathrm{O}(150 \mathrm{~mL})$ for $4 \mathrm{~h}$ at $-20{ }^{\circ} \mathrm{C}$. The solution was filtered and the filtrate concentrated in vacuo. After addition of $20 \mu \mathrm{L}$ of $\mathrm{CH}_{2} \mathrm{Br}_{2}$ as an internal standard, ${ }^{1} \mathrm{H}$ NMR analysis allowed measurement of a quantitative yield.

11 F. Bonet, C. Guéry, D. Guyomard, R. Herrera Urbina, K. TekaiaElhsissen and J. M. Tarascon, Int. J. Inorg. Mater., 1999, 1, 47-51.

12 U. R. Pillai and E. Sahle-Demessie, J. Mol. Catal. A: Chem., 2004, 222, 153-158.

13 A. L. Garay, A. Pichon and S. L. James, Chem. Soc. Rev., 2007, 36, 846-855.

14 Z. Du, W. Zhou, L. Bai, F. Wang and J.-X. Wang, Synlett, 2011, 369-372. 